\title{
Psychotic Depression: Diagnosis, Differential Diagnosis, and Treatment
}

\author{
Steven L. Dubovsky ${ }^{a}$ b Biswarup M. Ghosh ${ }^{a} \quad$ Jordan C. Serotte ${ }^{a}$ \\ Victoria Cranwell ${ }^{\mathrm{a}}$ \\ a Department of Psychiatry, Jacobs School of Medicine and Biomedical Sciences, University at Buffalo, Buffalo, NY, \\ USA; ${ }^{b}$ Departments of Psychiatry and Medicine, University of Colorado School of Medicine, Denver, CO, USA
}

\section{Keywords}

Affective disorders · Antidepressants · Antipsychotics .

Bipolar depression - Depressive disorder . Psychosis .

Psychotic depression · Mood disorders

\begin{abstract}
Psychotic depression was initially considered to be at one end of a continuum of severity of major depression. Subsequent experience demonstrated that psychosis is an independent trait that may accompany mood disorders of varying severity. While much has been learned about the impact of severe mood congruent delusions and hallucinations on the course and treatment response of depression, less is known about fleeting or mild psychosis, mood incongruent features, or psychotic symptoms that reflect traumatic experiences. Acute treatment of psychotic unipolar depression generally involves the combination of an antidepressant and an antipsychotic drug or electroconvulsive therapy. There is inadequate information about maintenance treatment of unipolar psychotic depression and acute and chronic treatment of psychotic bipolar disorder. Decision-making therefore still must rely in part on clinical experience.
\end{abstract}

(c) 2020 S. Karger AG, Basel

\section{Introduction}

Some clinicians believe that because modern rapid treatment of depression prevents it from becoming more severe, the development of psychotic features is now rare. In fact, psychotic depression remains a common condition that is often underrecognized and inadequately treated. This review addresses the complex ways in which psychosis can complicate mood disorders and the ways in which it alters their course and treatment response. Typical features that have been studied formally are outlined, and case examples are used to illustrate more subtle or complex presentations and treatment approaches.

\section{Evolution of the Concept of Psychotic Depression}

The definition of psychotic depression has evolved so much over the years that it is difficult to apply experience with earlier diagnostic criteria to more recent experience [1]. As psychosis was defined in the second edition of the Diagnostic and Statistical Manual of Mental Disorders (DSM-II) [2] as being so impaired mentally that the patient could not adapt to "the ordinary demands of daily life" [3], psychotic depression was defined solely by severe 
impairment [4], with or without the presence of delusions and hallucinations, which are traditional defining features of psychosis [3]. In this formulation, psychotic depression is at one end of a spectrum of severity and not a distinct disorder.

After reports that major depression with delusions had a different treatment response than major depression without delusions [3], the definition of psychotic depression was modified in DSM-III [5] to require delusions, hallucinations, or depressive stupor [3]. Although DSMIII eliminated severe impairment as the primary criterion for psychosis, this criterion remained in the International Classification of Diseases (ICD), especially if endogenous features were present [1]. In ICD-10 [6], the version that will continue until 2022, psychotic depression is still classified as a type of severe major depression [4]. However, the subsequent version (ICD-11) [7] includes hallucinations and delusions along with severity as diagnostic criteria. In other diagnostic systems, the concept of psychotic depression has variously included a level of severity that leads to distortion of reality, melancholic depression, endogenous depression, or the opposite of neurotic depression (defined in this context as depression with a psychosocial etiology) [8]. All of these classifications considered psychotic depression to be a severe subtype of major depressive disorder (MDD). An implication of this concept is that a more severe version of MDD may simply require more of the same treatment as other presentations, rather than a different therapeutic approach required by a distinct illness.

In DSM-IV [9], psychotic depression became a severe subtype of MDD characterized by delusions or hallucinations [4]. In DSM-5 [10], psychotic depression is still a subtype of MDD rather than a separate disorder, but the psychosis specifier is independent of severity, so that depression does not have to be severe to justify a diagnosis of psychotic depression [4]. In fact, DSM-5 permits psychotic features with dysthymia as well as major depression, acknowledging the idea that psychotic features are not just a function of severity of depression [11]. This change reflects an understanding that many depressive disorders can occur with or without psychosis, with different implications for treatment and prognosis [12].

Accumulating research supports the impression that psychosis is not inextricably linked to severity of depression [11]. In a study of 357 inpatients (mean age 56-58 years, mean length of stay 44-50 days) with ICD-10 severe depression, one-third of whom had psychotic features, higher scores in psychotically depressed patients on the 12-item Health of the Nation Outcome Scales (Ho-
NOS) severity rating scale were entirely attributable to the hallucinations/delusions subscale [13]. When psychosis was defined only as the presence of hallucinations or delusions, severity of depression was similar in the psychotic and nonpsychotic groups, and severity of depression was only weakly correlated with severity of psychosis [13]. In a recent prospective study of 288 depressed inpatients, severity of depression was equivalent in the $45 \%$ of patients with psychotic and the $55 \%$ with nonpsychotic depression, although functional impairment was greater in the psychotic patients [14].

While psychotic depression is often severe, patients may have equally severe depression without psychosis [12], and some cases of depression without hallucinations or delusions are associated with greater depression severity than are cases of depression with psychosis [13]. Since nonpsychotic episodes in patients with a history of psychotic depression are often briefer than, and not as severe as, psychotic episodes, it may be that a certain level of severity of the mood disorder is necessary for a propensity of psychosis initially to emerge [15]. Once it does, which is often after several episodes of nonpsychotic depression, psychosis tends to recur with subsequent episodes, which may not be as severe [16]. Although psychosis may not inevitably accompany every subsequent depressive episode, once it has occurred it functions as an independent feature of depression that alters the mood disorder in fundamental ways [13] that differentiate it from other forms of depression $[11,17]$. Insofar as it is psychosis rather than severity of depression that appears to alter the course and treatment response of mood disorders, an essential clinical task is to identify psychosis in depressed patients, particularly those who are not responding as expected to antidepressant therapy. In clinical practice, psychosis may be less obvious than it is in patients who have been studied in clinical trials.

Case example: A 30-year-old graduate student had been treated with multiple antidepressants for depressed mood associated with anhedonia, early morning awakening, low energy and motivation, decreased appetite, and social withdrawal. He had experienced a previous major depressive episode (MDE) that responded well to a single antidepressant and remitted completely. The antidepressant was continued for 1 year and then withdrawn, after which he remained well for 2 more years. A recurrence of depression precipitated by a romantic disappointment did not respond to the same antidepressant. Despite cognitive dysfunction consisting primarily of difficulty concentrating and mild dissociative symptoms, the patient continued to do well academically. He was less sociable because he felt that people might be laughing at him, but he was not profoundly withdrawn. He was cooperative with the clinician, but when pressed about how he felt about being examined, he said that he thought that the clinician might be gathering information 
to be used against him for unspecified purposes. He sometimes thought that he heard whispering, but he was not sure. When asked about noticing unusual smells, he replied, "just rotting flesh." In reply to inquiry about other unusual sensations, he said, "just a taste of blood." Addition of an antipsychotic drug resulted in remission of all symptoms.

Changing diagnostic criteria make it difficult to interpret research over the years in psychotic depression. The clinical and theoretical implications of a study depend on whether psychosis is defined by delusions and/or hallucinations, or by severity, impairment, or melancholia, whether MDEs were unipolar or bipolar, and whether the control group consisted of MDD of similar severity without psychosis, psychosis without depression, or melancholic versus nonmelancholic depression $[8,15]$. Interpretation of the results is further complicated by the question whether subjects had a past but not current history of psychosis, or whether they were currently psychotic [12].

Differing definitions and assessment methods have contributed to varying estimates of the prevalence of psychotic depression. Prevalence has been reported to be $4 / 1,000$ adults in the general population and 14-30/1,000 of those over age 60 [4]. In community samples, 10-19\% of adults with a MDE have been reported to have psychotic symptoms [12]. Studies in specialty settings suggest that psychotic features are present in $6-25 \%$ of patients with MDD [4, 18-21]. Around $25-45 \%$ of all adult inpatients with $\mathrm{MDD}$, and $24-53 \%$ of geriatric patients hospitalized for depression, have been reported to have psychotic features $[4,14,18,22]$. Since psychotic symptoms are often overlooked in depressed patients, the true prevalence of psychotic depression is likely to be underestimated [4].

\section{A Transdiagnostic Psychosis Trait}

Although the association has been questioned [4], a family history of diverse psychotic disorders including schizophrenia, psychotic bipolar disorder, and psychotic major depression is more common in psychotic than nonpsychotic depression [23-25]. Furthermore, there is some evidence that the content of delusions and hallucinations may be similar in psychotic relatives of psychotically depressed patients, regardless of the actual psychotic disorder [26], suggesting a transdiagnostic psychosis phenotype that overlaps affective and nonaffective psychotic syndromes $[27,28]$. This phenotype may be more strongly expressed in bipolar disorder, in which a family history of schizophrenia occurs in $14 \%$ of patients, while
$15 \%$ of schizophrenia probands have a bipolar family history [29]. The transdiagnostic property of psychosis is supported by a Danish birth cohort study showing that subclinical psychotic experiences at age 11-12 were associated with a family history of psychosis, but no particular psychotic disorder diagnosis [28].

Such research suggests that psychosis is a trait that can occur in a variety of disorders including schizophrenia, schizoaffective disorder, bipolar disorder, MDD, and possibly other conditions complicated by psychotic features such as posttraumatic stress disorder (PTSD), certain personality disorders, and delusional disorder. The psychosis trait may be transmitted independently of other features such as dysregulation of mood or thought [30]. Thus, association of a psychosis trait with dysregulated mood may produce a psychotic mood disorder phenotype, while confluence of the capacity for psychosis and disordered information processing may characterize schizophrenia. Accumulating evidence exists, particularly for bipolar mood disorders, that psychosis itself does not distinguish between categorical diagnoses; indeed, the content of psychosis and the presence of thought disorder by themselves do not distinguish between schizophrenia and psychotic bipolar disorder [31]. However, when psychosis is present, the primary disorder is more severe and produces more impairment and a worse prognosis $[28,29,32]$.

An independently transmitted psychosis trait has been thought to be linked to a relatively small number of gene sequences on the $\mathrm{X}$ and $\mathrm{Y}$ chromosomes (protocadherin $\mathrm{XY}$ ) coding for brain cell adhesion molecules that influence cerebral laterality and that played a role in the evolution of human language [33]. In the case of mood disorders, the threshold for expression of the psychosis trait may be lowered by epigenetic changes associated with the primary mood disorder, resulting in the appearance of psychosis once the mood disorder reaches a certain level of severity [34]. It may be that other reports of similar genetic markers in psychotic unipolar and bipolar depression, schizophrenia, and schizoaffective disorders are the result of markers of vulnerability to psychosis, not to any specific categorical diagnosis.

\section{Mood Congruent and Mood Incongruent Psychotic Symptoms}

The diagnostic and prognostic importance of mood congruent (i.e., reflective of a depressed or manic mood) and mood incongruent psychotic symptoms in mood 
disorders is the subject of ongoing discussion. Some investigators propose that mood incongruent psychotic features indicate a distinct subtype of psychotic depression with a worse prognosis regardless of the severity of depression [35]. This point of view appeared to be supported by a finding that mood incongruent psychotic features aggregated in families and predicted a more severe course [36]. In the Research Diagnostic Criteria, mood disorders with mood incongruent psychotic symptoms are grouped under schizoaffective disorder, based on the concept that mood incongruence conveys a worse course of mood disorders [37]. On the other hand, there is considerable heterogeneity of outcome in these patients [38].

Outcome studies of psychotic depression with mood incongruent symptoms are difficult to interpret because of lack of consistency of criteria for inclusion of subjects in this category. For example, at what point is a delusion considered to be mood incongruent? Are delusions of persecution by the devil, the FBI, or spirits in different categories? Even if there is a clear consensus on what constitutes mood incongruence, do all psychotic symptoms have to be mood incongruent? How do investigators classify patients for whom $50 \%$ of psychotic symptoms are mood incongruent? What about $10 \%$ or one mood incongruent symptom? Since the Research Diagnostic Criteria for schizoaffective disorder are different from the DSM criteria, which are based on psychotic features in the presence of a normal mood, even with agreement about the definition of mood incongruence, all studies of this diagnosis are not comparable.

Regardless of how psychosis is categorized, the bulk of evidence suggests that there is no difference in outcome between psychotic depression with mood congruent versus mood incongruent symptoms $[35,39,40]$. One point about which there is growing consensus is that mood incongruent psychotic symptoms convey greater likelihood of bipolar than unipolar depression $[12,25]$.

\section{Psychotic Depression and Bipolar Disorder}

Psychotic depression is more likely than nonpsychotic depression to have a bipolar outcome $[1,41]$, and episodes of bipolar depression are more frequently associated with psychotic symptoms than are episodes of unipolar depression [42]. Indeed, a strong predictor of psychosis in the course of a mood disorder is bipolarity [15]. Of adults with psychotic depression in community samples, $48.5 \%$ have received a diagnosis of bipolar I, and
$10.5 \%$ a diagnosis of bipolar II, mood disorders [12]. An eventual diagnosis of bipolar disorder is especially common in early-onset psychotic depression $[4,43]$. Relatives of patients with psychotic depression have a higher rate of bipolar disorder than relatives of patients with nonpsychotic depression, and depressed relatives of patients with bipolar disorder are more likely to have psychotic features than are depressed relatives of controls [4]. As in unipolar depression, psychosis accompanying bipolar disorder is associated with an earlier age at onset of the mood disorder, more affective symptomatology and chronicity, a greater number of admissions, longer hospitalizations, more psychiatric comorbidity, and a poorer prognosis [44].

One feature of bipolar psychotic depression that has not received much attention in the literature is the degree to which mixed elements of elevated mood and energy can result in patients not appearing to be as depressed as they feel, and for patients with psychotic symptoms to function at a higher level than would be predicted by the degree of symptomatology. Such patients' symptoms may be dismissed as exaggerated or indicative of a personality disorder, making the clinician overlook the actual diagnosis. Another feature of bipolar psychotic depression that is easily overlooked is the frequent occurrence of nonauditory hallucinations. Visual hallucinations have been noted to occur more frequently in bipolar than in unipolar depression [45], but olfactory and haptic hallucinations are not rare either. Dramatic, mood incongruent hallucinations may be minimized by patients who are not necessarily disturbed by them, requiring persistence to reveal the psychosis.

Case example: A 20-year-old student with a MDE did not appear depressed or withdrawn even though he endorsed multiple depressive symptoms. He denied seeing things that other people did not see. However, when asked whether he ever saw something moving out of the corner of his eye, he replied "like a bat?" When asked next whether he ever saw a bat, he replied that he did not. In reply to the question "what else don't you see," he said "I don't see rats crawling all over my feet." The next question was "why not," to which the patient replied, "because it would mean the devil sent them." How long had the devil been sending animals to torment him? For the past 4 years. This was about the same time he developed a headache that felt like his head was swelling. Why had he not mentioned these experiences? He did not want people to think that there was something wrong with his mind. A more careful review of affective symptoms prompted by elicitation of these symptoms revealed that the patient only slept $2-3 \mathrm{~h}$ per night, that he had continually racing thoughts previously diagnosed as obsessions, and that he had become increasingly irritable and impulsive with treatment with antidepressants. 


\section{Covert Psychotic Depression}

Depressed patients may minimize or not report psychotic symptoms because they do not think that they are abnormal, they do not want to be considered ill, or they want to be left alone. Some patients may not recall psychotic symptoms they experience in one mental state (e.g., when they are manic) at a time they are in another state (e.g., when they are depressed). As in the previous example, some patients may not think abstractly enough to answer broad general questions such as whether they see things or hear things or whether they feel persecuted, but they may be forthcoming if they are asked about specific hallucinations and delusions. Features often associated with psychotic depression that can serve as clues to the presence of psychosis in patients who initially deny such symptoms are summarized in Table $1[11-13,15,19$, $23,24,46-48]$.

\section{Juvenile Psychotic Depression}

In community samples, $9-35 \%$ of children and $5-11 \%$ of adolescents endorse hallucinations [49-51]. However, psychotic-like experiences in younger patients are difficult to interpret because children normally have difficulty distinguishing fantasy from reality, perhaps explaining why $75-90 \%$ of such experiences are transient $[12,52]$. On the other hand, a systematic review and meta-analysis of 14 studies from 13 different community samples $(n=$ $29,517)$ found that childhood psychotic experiences conveyed a three- to fourfold increased risk of a mood or psychotic disorder [51]. A study of 20,000 patients aged 15 years or older found that $18.5 \%$ of subjects who met the criteria for a MDE had psychotic features [12]. Up to $60 \%$ of children hospitalized for depression have been reported to have psychotic symptoms [50]. Since many younger patients do not tell their parents about psychotic symptoms $[49,50]$, the prevalence of psychotic symptoms in depressed children and adolescents is probably underestimated.

Among patients with psychotic mood disorders, hallucinations are more common in children and adolescents than in adults [50]. Hallucinations occur in as many as $80 \%$, and delusions occur in $22 \%$, of psychotically depressed youth [49]. Auditory hallucinations are most common, but they are often accompanied by visual, olfactory, and/or haptic hallucinations [12, 50], while delusions are less common [12]. The most common delusions in juvenile patients are delusions of ref-
Table 1. Clinical clues to psychosis in depressed patients

\section{Symptoms}

Severe early morning awakening

Extreme agitation or retardation

Overvalued self-reproach, guilt, and somatic preoccupation

Marked perplexity and cognitive dysfunction

Significant dissociation

\section{Course}

Early or postpartum onset of severe depression

Poor antidepressant response

Family history/neurobiology

Family history of psychosis

Previous episodes of psychotic depression

Sleep onset REM/hypnogogic hallucinations

High post-dexamethasone cortisol on dexamethasone suppression test

Imaging findings

Small hippocampal volume

Enlarged ventricles

erence, mind reading, and thought broadcasting [49]. Children may not report delusional ideas out of fear of being punished for saying things that adults might think are not true [12]. Any psychotic symptoms in younger depressed patients increase the likelihood of a bipolar outcome [12, 49].

Case example: A 14-year-old boy was being treated for a MDE and a tic disorder. The latter diagnosis was based on repetitive, nearly identical, torticollis-like movements of his head. The movements seemed to be directed toward a spot that was always to the patient's left. Finally, the patient was asked what he kept looking at. The patient replied, "that goblin sitting on the desk." What was the reason the patient had not mentioned the hallucination previously? He thought everyone saw it.

\section{Mild and Transient Psychotic Symptoms}

Research into the phenomenology and treatment of psychotic depression has primarily involved patients with easily identifiable, blatant psychotic symptoms. However, psychosis is a continuous rather than dichotomous phenotype across clinical diagnoses and subclinical psychotic-like experiences in the otherwise healthy general population [53]. Yet, little is known about whether the impact of subtle or intermittent psychotic symptoms on the course and treatment response of mood disorders is similar to that of more obvious psychosis. 
Brief, "nondiagnostic" psychotic experiences occur in about $7-10 \%$ of the general population, $17 \%$ of children aged $9-12$ years, and $7.5 \%$ of teenagers $[12,28]$. However, these symptoms are qualitatively different from clinically relevant psychosis [54]. For example, paranormal beliefs and magical thinking without impairment are much more likely to be experienced by people who are not ill than are paranoia, bizarre experiences, and hallucinations, which are more likely to be associated with distress and disability [55]. Subclinical psychotic experiences are transient in $80 \%$ of people, but $20 \%$ may develop persistent psychotic experiences, and $7 \%$ end up with a psychotic disorder [28], with an annual transition rate to psychotic disorder of $<1 \%$ [28]. Persistence of psychosis is more likely in people with past traumatic experiences or a family history of any psychotic disorder [28]. Ultrahigh-risk individuals, who have multiple subclinical psychotic experiences, have higher annual transition rates to psychosis [28], with a risk of developing a psychotic disorder within 1 year of $22 \%$ and a risk of $36 \%$ after 3 years [55].

According to Carlson [12], "psychotic symptoms that are detailed and dramatic or in which content is associated with past traumatic experiences, or only present when the person is angry, or while negotiating for some particular need to be met, are unstable and do not represent true psychosis. These symptoms, even when they occur in the context of a depressive state, probably do not represent true affective psychosis" (p. 571). Bebbington [56] agrees that "there is a (rational) reticence to diagnose a psychotic disorder if the psychotic symptoms are only experienced rarely, or occur singly, especially if the person is undisturbed by them and has insight" (p. 128). Within the clinical spectrum of hallucinations and delusions in mood disorders, however (as opposed to the clinically well general population), it is not known whether milder symptoms have the same significance as more severe ones. For example, do nondistinct voices to which the patient pays no attention or that the patient thinks might be imaginary have the same diagnostic and prognostic significance as persistent accusations of sin from a supernatural source? Or does the intermittent feeling that people might be spying on the patient have the same impact on course or treatment response as the conviction that the patient is being persecuted? At which point does intense rumination become delusional [57]? The threshold of severity or persistence for altering the course of mood disorders is yet to be determined [46].

\section{Psychotic Depression and Trauma}

A history of childhood trauma is $2-15$ times higher in psychotic than in nonpsychotic depressed patients [20]. In a study of 500 psychiatric outpatients, patients with psychotic depression were four times as likely to have comorbid PTSD as were those without psychotic depression (57.9 vs. $15.7 \%$; $p=0.0001$ ) [58]. The observation that combat-related PTSD has a $30-40 \%$ incidence of psychotic symptoms [59] raises the question whether such individuals have PTSD with comorbid psychotic depression, whether PTSD with psychosis is a distinct PTSD subtype [60], or whether, in contrast to depression, psychotic symptoms in PTSD have no particular diagnostic or therapeutic significance. Psychotic symptoms in PTSD may or may not reflect the trauma; cases in which they do not could be cases of PTSD with comorbid psychotic depression rather than psychotic PTSD [59]. Along these lines, some clinicians question whether psychotic symptoms that reflect traumatic experiences represent "real" or "pseudo" psychosis. Hallucinations and delusions in this formulation represent flashbacks or dissociative reexperiencing of elements of trauma, although empirical evidence supporting this formulation is variable [61]. In 73 women being treated for PTSD related to childhood abuse and neglect, $46-91 \%$ endorsed hearing voices on one or both of two standardized instruments [62]. The authors considered such symptoms, which were more likely to be present on instruments that asked multiple questions about them, to be dissociative experiences distinct from "true" psychotic symptoms. Interestingly, there was no difference in the use of antipsychotic drugs between patients who did or did not hear voices. There is mixed evidence to determine whether antipsychotic medications are reliably useful in PTSD with psychosis $[60,63]$, or whether psychotherapy alone resolves "psychotic-like symptoms" in PTSD [64].

Since depression is a common feature of PTSD, psychotic depression in a patient with a history of trauma can be very difficult to differentiate from PTSD with psychotic features [23]. Whether or not symptoms of comorbid PTSD are present, it is not known whether psychotic symptoms that directly reflect traumatic experiences in a depressed patient ("trauma congruent" psychotic symptoms) have different therapeutic or prognostic implications than mood congruent psychotic symptoms. The speculation that some of the relative treatment resistance reported with psychotic depression may be due to unrecognized PTSD [58] has not been studied. It is not yet clear whether treatment of the combination of posttraumatic 
symptoms, depression, and psychosis should be similar to the treatment of psychotic depression in the absence of a significant trauma history.

Case example: Following the fall of Saigon, a man who had served as an officer in the South Vietnamese army was tortured by the new government in a re-education camp. He escaped and left Vietnam with a group of refugees who were further traumatized when they were captured by pirates in the South China Sea. After making his way to the United States, he supported himself and the family he established by working at several jobs. Years after settling in a suburban neighborhood, he was in a motor vehicle crash that was startling but caused no injuries. The man had no initial reaction, but a few weeks later he became agitated and hypervigilant, with an increasing sense of being in danger from unknown sources. Along with insomnia, bad dreams he could not remember, and restlessness, he developed crying spells, loss of appetite, difficulty concentrating, anhedonia, and guilt, although he could not say exactly what he felt guilty about. As he became more tearful and withdrawn, he began to hear the voices of fellow soldiers who had been killed during the war telling him that he did not deserve to live and should join them. The sense of being in danger evolved into the belief that he was going to be killed by an unseen enemy.

Attempts to address the relationship of the current symptoms to traumatic experiences during and after the war intensified all symptoms, as did a discussion of the losses he had suffered at that time. In view of the prominent depressive symptoms, he was treated with an antidepressant, with modest improvement. After an extensive discussion about whether the psychotic symptoms were simply dissociative experiences that reflected activation of PTSD by the shock of the crash, an antipsychotic medication was added. As the dose was increased, all symptoms remitted completely. At that point, he was able to discuss his earlier experience and begin active grieving of the losses of wartime comrades and his homeland.

\section{Depression Complicating Psychosis}

Traditionally, the term psychotic depression refers to a primary mood disorder that is complicated by psychosis. Much less information is available about primary nonaffective psychoses complicated by depressive episodes. Within this group, the largest body of data concerns schizophrenia. Estimates of the prevalence of depressive episodes in schizophrenia have ranged from 27 to $48 \%$ [65-67], while in one study $31 \%$ of patients aged $>55$ years with schizophrenia spectrum disorders had subsyndromal depressive symptoms [67]. Comorbid depression in schizophrenia is associated with more positive and negative symptoms and greater suicidality [67, 68]. Despite substantial overlap between depressive and negative symptoms, low mood, pessimism, and suicidality are more specific to depression, while alogia and blunted affect are more reliably linked to negative symp- toms [69]. Despite evidence that depressive and negative symptoms represent distinct domains in schizophrenia, antidepressants may improve the latter [70-72], although not all studies agree [73] and it is often not clear whether patients who responded were also depressed.

The assessment of depressive symptoms in patients with schizophrenia can be complex. For one thing, it can be difficult to distinguish between depressive and negative symptoms. Bradykinesia and affective blunting caused by antipsychotic drugs can also mimic depression, and antipsychotics with more potent $\mathrm{D} 2$ blockade may be associated with dysphoria [74]. A recent review suggested that sulpiride, amisulpride, clozapine, olanzapine, aripiprazole, quetiapine, and lurasidone may be somewhat more effective than other antipsychotics in ameliorating depressive symptoms in schizophrenia [74]. In an 8-week clinical trial, both amisulpride and olanzapine reduced depressive symptoms in schizophrenia patients, with 62$66 \%$ of patients rating as "much" or "very much" improved on the Clinical Global Impression Scale [75]. Conversely, the review cited above suggested "modest effectiveness" for depression accompanying schizophrenia of adding an antidepressant [74]. In a study of 175 schizophrenia patients with comorbid MDD, antidepressants reduced depression scores and produced remission of depression in $56 \%$, without improving schizophrenia symptoms [66]. No antidepressant appeared more effective than any other, while nonresponse was predicted by more severe paranoia and comorbid substance use disorders. A 12 -week open-label study found the antidepressant agomelatine to be effective for depressive and negative symptoms and global psychopathology, but not positive symptoms, in patients with schizophrenia and MDD, although pharmacokinetic interactions with antipsychotic drugs sometimes occurred [76].

\section{Treatment}

Psychotic depression has a low rate of spontaneous recovery [77]. In early studies, the placebo response rate was close to zero [78], but recent studies report a response rate to placebo as high as $30 \%$ [79]. In contrast to less complicated forms of depression, the response to psychotherapy alone has been known for some time to be negligible $[77,78,80]$, although cognitive approaches can improve coping in mood disorder patients with delusions [81]. Other psychotherapies that have been used adjunctively include behavioral activation, acceptance and commitment therapy, and acceptance-based depression and 
psychosis therapy (a combination of behavioral activation and acceptance and commitment therapy) [4]. Nevertheless, somatic therapies remain a mainstay of treatment.

The pharmacologic approach to psychotic depression depends on whether psychosis is conceived of as one end of a continuum of severity in depression or a distinct entity. If it is simply very severe major depression, an antidepressant alone at the right dose should be effective, possibly with one of the standard augmentation agents. If psychotic depression is a distinct disorder, treatment both for psychosis and depression would be necessary [82]. To address this question, initial studies of pharmacotherapy for psychotic depression involved tricyclic antidepressants (TCAs) and/or first-generation antipsychotic drugs (neuroleptics). A review of randomized studies between 1966 and 2004 [18], only one of which employed a placebo arm, reported response rates to amitriptyline, perphenazine, or the combination of 41,19 , and $78 \%$, respectively; in another study included in that review [83], response rates were $86 \%$ with amitriptyline plus perphenazine and $82 \%$ with amoxapine, a metabolite of the antipsychotic drug loxapine that has both antidepressant and antipsychotic properties [18]. An updated systematic review of 12 RCTs in 11 publications involving a total of 929 patients confirmed that the combination of an antidepressant and an antipsychotic drug (combination therapy) was more effective in reducing depressive symptoms in psychotic depression than either one alone or placebo [82]. The finding was limited by considerable variability between studies as well as patient heterogeneity and potential for bias. A meta-analysis of 8 acutephase RCTs in 762 adults with psychotic depression performed through February 2011 found that combination therapy was significantly superior to antidepressant monotherapy for ratings of efficacy and severity of illness, but not psychosis or anxiety ratings [84]. A finding of no superiority over 2 weeks of addition of perphenazine to nortriptyline (mean dose $19 \mathrm{mg} ; n=17$ ) versus placebo in psychotically depressed patients who did not respond to 2 weeks of nortriptyline monotherapy [85] may have been the result of too short a trial of too low a dose of the antipsychotic. A comparison of the monoamine oxidase inhibitor (MAOI) phenelzine in doses up to $90 \mathrm{mg} /$ day and adequate platelet monoamine oxidase inhibition in nonpsychotic and psychotic major depression found a $68 \%$ response rate in the former but only $21 \%$ in the latter, suggesting that MAOI monotherapy is not more effective than TCA monotherapy in psychotic depression [86].

Psychotic Depression
Studies of newer antipsychotic drugs and antidepressants in psychotic depression have mainly involved a few second-generation antipsychotics and SSRIs. An industry-sponsored, multicenter study consisted of two 8-week double-blind trials (124 patients in one trial, 125 in the other; mean age 41 years) [87]. Patients the majority of whom had mood congruent psychotic symptoms were randomly assigned to placebo, olanzapine, or the combination of olanzapine and fluoxetine. Modal doses were $11.9-14.5 \mathrm{mg}$ of olanzapine and $22.6-23.5 \mathrm{mg}$ of fluoxetine. Only $42-47 \%$ of patients completed the trials. In one trial, the combination of olanzapine and fluoxetine was significantly more effective than placebo, with a decrease in Hamilton Depression Rating Scale (HDRS) scores from 38.4 to 20.9. There were no differences between groups in the other trial. The Study of Pharmacotherapy of Psychotic Depression (STOP-PD) was a fourcenter, 12-week, double-blind comparison of remission rates (defined as HDRS score $\leq 10$, not meeting criteria for MDD, and absence of psychosis) in 259 psychotic depression patients (mean age 58.8 years) randomly assigned to olanzapine (average dose 14-15 mg) plus placebo, or olanzapine plus sertraline (average dose 169-170 mg) $[79,88-90]$. Patients had to have at least one moderately severe delusion. None of the patients had hallucinations in the absence of delusions. Following randomization, $63 \%$ of combination therapy patients and $47 \%$ of monotherapy patients completed the double-blind study [88]. Remission rates were $42 \%$ for combination therapy versus $24 \%$ with olanzapine monotherapy $(p=0.002$; $\mathrm{NNT}=5.5)$; statistical separation began at week $8[88,91]$. At the end of the study, $45 \%$ of patients still had psychotic symptoms, with no significant differences between groups [89]. Based on rating scale scores, the superiority of combination therapy to olanzapine plus placebo was attributable to a better antidepressant effect and not a better antipsychotic effect [41].

In a 7-week RCT of 122 psychotically depressed patients, significantly more patients responded to $375 \mathrm{mg}$ of venlafaxine plus $600 \mathrm{mg}$ of quetiapine $(65.9 \%)$ than to venlafaxine alone $(33.3 \%)[21,92]$. The $59(48.4 \%)$ patients who responded ( $\geq 50 \%$ decrease in HDRS score and final score $\leq 14$ ) were followed openly for another 15 weeks, during which time 6 patients dropped out [21]. At week $22,92.5 \%$ of patients were still taking study medication, and $96.2 \%(51 / 53)$ of patients who completed maintenance therapy remained responders [21]. Remission rates (HDRS score 57 ) increased during maintenance from $35 / 59$ responders at week 7 of treatment to $46 / 53$ at week 22, without any differences between treatment 
groups [21]. At all points, improvement of depression tended to parallel improvement of psychosis [21].

A review of four psychotic depression RCTs that were not summarized previously included comparisons of venlafaxine versus venlafaxine plus quetiapine, olanzapine versus olanzapine plus sertraline, and trimipramine versus amitriptyline plus perphenazine [4]. Overall, combination therapy was superior to monotherapy with an antidepressant or an antipsychotic drug [4]. A meta-analysis of eight studies involving 784 patients confirmed that combination therapy was superior to antipsychotic $(\mathrm{NNT}=5)$ and antidepressant $(\mathrm{NNT}=7)$ monotherapy [84]. Conversely, addition of perphenazine (mean dose $19 \mathrm{mg}$ ) to therapeutic doses of nortriptyline in nortriptyline nonresponders did not improve the response rate [4]. Since nortriptyline levels were not reported, it was not clear whether the neuroleptic might have raised the nortriptyline level out of the therapeutic range.

In view of the possibility that it may take 8 weeks [ 88 , 91] or longer [21] to demonstrate a clear response to pharmacotherapy of psychotic depression, combination therapy may not seem superior to monotherapy if the duration of treatment was inadequate. Another reason for variable results with combination therapy may concern antipsychotic drug doses. Most studies have used low to moderate fixed antipsychotic doses. However, in older studies, doses up to $650-1,000 \mathrm{mg}$ of chlorpromazine or 24-64 mg of perphenazine were necessary to obtain a response [26]. A small study comparing responses of psychotic major depression to the combination of the TCA desipramine and neuroleptics in several doses found that all 6 patients treated with at least $45 \mathrm{mg}$ of perphenazine, but only 10 of 25 patients taking $32 \mathrm{mg}$ or less, responded; the greater response rate with the higher antipsychotic dose was not explained by changes in the TCA level [93]. On the other hand, patients with mood disorders may be more vulnerable to tardive dyskinesia [94] and other adverse effects that lead to treatment discontinuation [18]. The suggestion that some patients may need higher antipsychotic doses, which may have actions beyond dopamine D2 receptor blockade [46], has not been pursued in newer studies or in any studies of atypical antipsychotic drugs.

Most studies find the overall response rate to electroconvulsive therapy (ECT) of psychotic depression of 82$90 \%$ to be equivalent or superior to combination therapy $[4,79]$. However, the response rate to ECT in community samples is reported to be lower (30-47\%), possibly because more patients with comorbid medical conditions and other complications are included in these samples
[4]. In a meta-analysis of 44 studies of the treatment of psychotic depression between 1959 and 1988 that included studies of ECT, TCAs, MAOIs, antipsychotic drugs, and combinations of these treatments, including three studies using simulated ECT as a control [95], ECT (especially bilateral ECT) produced a higher response rate than TCA-antipsychotic drug combinations. It has been suggested that ECT is more effective for psychotic than nonpsychotic depression [4], although this contention is not clearly supported by controlled studies. Since ECT may reduce hospitalization time if initiated early and prolong it if initiated later, ECT should be a first-line treatment for suicidal or incapacitated psychotically depressed patients [4].

Guidelines from the UK, Denmark, and the Netherlands recommend antidepressant monotherapy as firstline treatment, apparently based on the 2005 Cochrane report mentioned earlier that did not find combination therapy to be superior to antidepressant monotherapy [96]. However, since a subsequent review and meta-analysis of RCTs found that combination therapy was significantly more effective than antipsychotic or antidepressant monotherapy [84], and since most research and a later Cochrane report favor combination therapy or ECT for unipolar psychotic depression $[4,82,88,90]$, the American Psychiatric Association (APA), Canadian Psychiatric Association, South African Psychiatric Association, Australia/New Zealand and international guidelines, and the Texas Medication Algorithm Project (TMAP) all endorse combination therapy as first-line treatment [18]. These guidelines do not endorse specific medication regimens in view of inadequate data to support one medication over another [4]. No guideline recommends antipsychotic monotherapy. The APA, Canadian, TMAP, Denmark, and international guidelines also recommend ECT as first-line treatment, while the UK, Australia/New Zealand, and international guidelines endorse ECT as the first-line treatment in the presence of severe suicidality or a "threatening somatic condition" [4, 18]. Overall, there is a significant lack of consensus on the treatment of psychotic depression, both in treatment guidelines and among practicing psychiatrists, especially in terms of specific agents and doses $[4,47]$. Regardless of the standard that is adopted, however, only $5 \%$ of psychotically depressed patients receive adequate treatment [4].

Although manualized psychotherapies such as cognitive behavior therapy and interpersonal therapy are effective for many cases of MDD, the presence even of mild psychotic symptoms reduces the response to psychother- 
apy [97]. A number of individual and group psychological interventions have been found to improve symptoms and functioning in psychosis, particularly schizophrenia [98-101]. However, the applications of these therapies in psychotic depression have not been studied. Similarly, psychotherapies for prodromal or attenuated psychosis that have been found to be promising have not been studied in depression associated with mild psychotic symptoms.

Psychotherapy is generally considered the most appropriate initial treatment of childhood depression [102], although a Cochrane review concluded that the relative benefits of pharmacotherapy, psychotherapy, or the combination thereof have not been clearly demonstrated empirically [103]. Psychological interventions for psychosis in adolescence appear to be helpful for cognition and functioning, if not psychosis itself [104]. However, there is very little empirical information about psychotherapy in juvenile psychotic depression.

\section{Augmentation}

Augmentation with lithium in four small, uncontrolled studies improved the response rate of psychotic depression, especially bipolar psychotic depression, to combination therapy [4]. In one report, open augmentation of antidepressant-antipsychotic combination therapy with carbamazepine was effective in 3 patients [105]. There has been more systematic interest in brief augmentation with mifepristone, an antagonist of the progesterone receptor and the glucocorticoid receptor type II, which has a low affinity for cortisol and helps terminate the stress response [19]. Since high levels of cortisol reported in psychotic depression could disinhibit dopamine release and contribute to psychosis, it has been hypothesized that adjunctive use of mifepristone might reduce psychotic symptoms in psychotic depression. An open-label trial of 6 days of mifepristone monotherapy in 20 inpatients with a DSM-IV MDE with psychotic features followed patients openly for a total of 8 weeks [106]. Psychotic symptoms improved significantly over the first 4 weeks, but not subsequently. In a doubleblind, placebo-controlled study, 221 patients with psychotic depression (mean age 41-42 years) were randomized to 7 days of monotherapy with mifepristone or placebo [19]. Mifepristone was then discontinued and patients were treated openly for another 3 weeks with whatever treatment the clinician preferred. During this phase, 58-62\% were treated with an antidepressant, 36$42 \%$ with an antipsychotic drug, $29-37 \%$ with combination therapy, and $2-3 \%$ with ECT. At 28 days in both intention-to-treat and completer analyses, mifepristone patients had higher rates of 50\% decrease of Brief Psychiatric Rating Scale (BPRS) positive symptoms. The effect of mifepristone was most marked for psychotic symptoms; there was no significant decrease in depression. A secondary analysis of a similar study that did not note an overall significant effect on BPRS score 7 weeks after a 1-week trial of treatment with mifepristone found that the results were four times more likely to be significant in patients with higher mifepristone plasma levels $(\geq 1,800 \mathrm{mg} / \mathrm{mL})$ [107].

\section{Course}

Relapse or recurrence has been reported within 2-14 months after recovery from an index episode of psychotic depression [21, 46]. A 2-year prospective follow-up of 56 patients (mean age 36 years) with a first episode of DSM-IV MDD with psychotic features found that 35\% had achieved true functional recovery [108]. Relapse or recurrence within 2 years of initial recovery occurred in $45 \%$ of 49 patients in this study; the mean time to a new episode was 57 weeks. The high rate of relapse may have been related to lack of adequate maintenance treatment: at 2 years, $51 \%$ ( 25 of 49 subjects) were not taking any medication, and most patients were not taking combination therapy. Similarly, a 10 -year follow-up found that psychotically depressed patients were three times less likely than non-psychotically depressed patients to have recovered from the index episode [109]. Depressive recurrences were ten times as likely to have psychotic features following a psychotic compared to a nonpsychotic episode [109]. Conversely, a long-term prospective study found that after 40 years of follow-up, outcomes were similar in psychotically and non-psychotically depressed patients $[110,111]$.

The question remains whether continuation of both the antidepressant and the antipsychotic drug is necessary to prevent relapse of psychotic depression. Earlier experience with combination therapy with neuroleptics suggests that discontinuing or even reducing the dose of the antipsychotic drug within the first year of recovery increases the risk of relapse, even if the antidepressant is continued $[4,18,22,112-114]$. A RCT of 26 weeks of maintenance treatment in psychotic depression found no difference between monotherapy with nortriptyline or sertraline versus one of these antidepressants plus perphenazine, but the sample size was very small and the results were probably not generalizable [4]. 
To address the lack of empirical data about maintenance therapy, a second STOP-PD openly treated 269 patients (mean age 55-56 years) with a MDE and at least one delusion with or without hallucinations to median daily doses of $150 \mathrm{mg}$ of sertraline and $15 \mathrm{mg}$ of olanzapine [115]. Of the 195 patients who completed 12 weeks of acute treatment, 162 met the criteria for at least 2 weeks of remission (no psychotic symptoms and 17-item HDRS score $\leq 10$ ) or near-remission (no psychotic symptoms and $50 \%$ reduction in HDRS score with a final score of 11-15; improved or very much improved on the Clinical Global Impression Scale). After an 8-week stabilization phase with combination therapy, 126 patients who still met the criteria for remission or near-remission were randomized to a 36-week trial of open-label sertraline plus double-blind olanzapine or placebo. During this phase, relapse occurred in $20 \%$ of patients receiving combination therapy versus $55 \%$ of patients receiving sertraline plus placebo (HR 0.25; $p<0.001$; NNT $=2.8$ ). Addition of olanzapine resulted in significantly more weight gain and waist circumference and less of a decrease in total cholesterol as well as significantly more Parkinsonism but not akathisia. In this study, relapse on placebo was associated with cortical thinning on MRI, but continuation of the antipsychotic drug was also associated with cortical thinning, suggesting that both the illness and its treatment have neurological risks [116]. Most of the excess risk of relapse with antidepressant monotherapy was during the first 2 months of double-blind treatment or 4 months after initial remission. However, since relapses continued throughout the trial, the duration of antipsychotic continuation that would prevent all relapses was not clear [117]. An editorial suggested that the results indicate that the antipsychotic drug should be continued for 4 months after remission, and possibly for a year or longer, after which the antipsychotic drug might be gradually discontinued, with reinstitution of the effective dose in response to any evidence of relapse [117]. It remains unclear whether the antipsychotic dose could be reduced without increasing relapse risk. The considerable hazards and benefits of continuing the antipsychotic drug remain to be clearly defined, as do optimal specific medications and doses $[4,117,118]$. There have been no antidepressant discontinuation studies in psychotic depression.

Case example: A successful architect had an episode of major depression at age 40 that responded well to an SSRI. She discontinued the medication after a year and remained well for 15 years, when she experienced a recurrence. She was treated with the same antidepressant, which was not effective. When she failed to respond to a second antidepressant, her husband revealed that she told him that she thought that her psychiatrist was conspiring with her boss to discredit a project she had been working on. After some discussion, she revealed that a number of people had been plotting to steal her ideas because they knew that she had been having trouble concentrating. Risperidone was added, and at a dose of $4 \mathrm{mg} /$ day the patient was improved but not well. When the dose was gradually increased to $8 \mathrm{mg} /$ day, she had complete remission of symptoms and returned to full-time work. Attempts to reduce the dose of the antipsychotic drug by $0.5-1 \mathrm{mg}$ at a time were repeatedly followed by relapse, which remitted when the previous dose was reinstituted. The patient remained well psychiatrically for 3 more years when she developed orofacial dyskinesia. Asserting that she could not live with a return of depression, she refused another attempt to withdraw the antipsychotic drug. She was unwilling to consider ECT. A vesicular monoamine transporter-2 inhibitor was not helpful. Gradual crossover to clozapine in an eventual dose of $700 \mathrm{mg}$ maintained remission of psychotic depression and minimized dyskinetic movements, making it easier for the patient to interact with colleagues. She continued to function well at work.

\section{Real-Life Treatment Recommendations}

As is true in nonpsychotic depression, clinical trials in psychotic depression usually exclude patients who are suicidal or homicidal, and those with significant comorbidity, especially of substance use and personality disorders. As noted earlier, recent studies of combination therapy have involved a small number of atypical antipsychotics and antidepressants in patients with primarily mood congruent psychotic symptoms. While doses of antidepressants are relatively well established, most clinical trials of antipsychotic drugs have been in primary psychotic disorders such as schizophrenia or in mania. In psychotic depression, there is only one dose finding study of first-generation antipsychotics and none of atypical antipsychotics. The current body of data therefore may not inform choices sufficiently for the clinician who treats subtle, complex, or refractory psychotic depression, bipolar psychotic depression, and psychotic depression with significant comorbidities. The following recommendations are based on the data reviewed above and our own experience over many years of treating patients with psychotic depression (Fig. 1).

Diagnosis is usually straightforward in patients who describe depression and obvious psychosis. The first diagnostic question is whether depression or psychosis is primary. In the case of a primary psychotic disorder, especially schizophrenia, complicated by a MDE, the currently available evidence suggests first reducing the dose of the antipsychotic drug or changing to one of the antipsychotics that have been thought possibly to be more helpful for depression or at least less likely to cause or ag- 
Fig. 1. Treatment decision-making in psychotic depression (see text). ECT, electroconvulsive therapy.

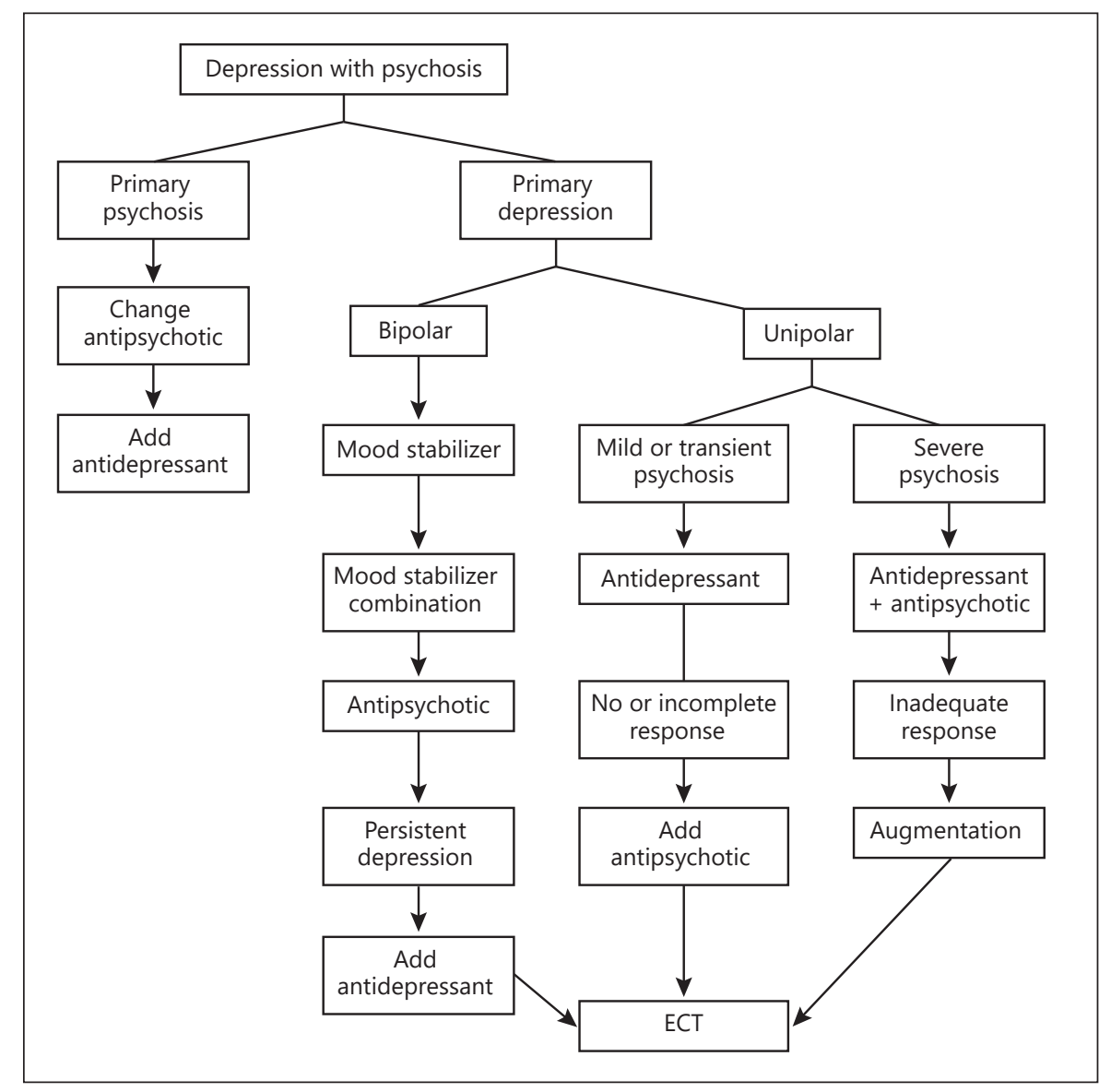

gravate dysphoria. The next step would be to add an antidepressant, with the expectation that depression and possibly negative symptoms will improve, but the overall course of schizophrenia may not change.

Since not all patients with primary mood disorders volunteer psychotic symptoms, it is prudent to inquire about them in patients who deny psychosis but fail to respond as expected to an antidepressant, especially when factors summarized in Table 1 that are often associated with psychosis are present. Patients who are embarrassed about psychotic symptoms, consider them insignificant, or fear that acknowledging them will result in hospitalization or some other perceived sanction may require indirect questions with more specific follow-up. For example, patients who deny seeing things that other people do not see may acknowledge that they sometimes see movement out of the corner of their eyes and with further questioning admit that it looks like a shadow or a person who seems to be following them.

When psychotic depression is identified, the first question is whether the mood disorder is unipolar or bipolar.
The differentiation is obvious in patients with a past history of mania or hypomania. However, especially in younger patients, this pole of the mood disorder may not yet have occurred or may not be obvious. The possibility of an underlying bipolar disorder should be considered in psychotically depressed patients with subtle hypomanic features such as intense irritability, aggression, or impatience, lack of sleep without feeling tired, increased sexual interest, lack of anhedonia, and increased physical or mental activity despite complaints of severe fatigue. A bipolar component may also be suggested by early onset, highly recurrent depression with an acute onset, dramatic psychosis that is not associated with impaired functioning, nonauditory hallucinations, hallucinations without delusions, bipolar first-degree relatives, or any mood disorder in multiple generations [43, 119-123].

Although data on the treatment of bipolar psychotic depression are sparse, experience in nonpsychotic bipolar depression suggests that antidepressants can be problematic [124-126]. Atypical antipsychotic drugs have theoretical appeal because some of them appear in short-term 
monotherapy trials to improve bipolar depression [127130]. However, it is not entirely clear that reduction in depression rating scale scores in these studies is not secondary to improvement of insomnia, anxiety, irritability, and related symptoms. In addition, the evidence that these medications are true mood stabilizers is not compelling [131], and metabolic, cognitive, and motor adverse effects can be troublesome, especially with longterm treatment. Consistent with observations in mania [132], we have found that psychosis may remit without an antipsychotic drug when mood improves. We therefore begin treatment with a mood stabilizer alone. Of the established mood stabilizers, lithium and carbamazepine may be more acutely effective for depression, although valproate is an appropriate first choice for male patients with prominent anxiety or irritability [133]. Simplicity of administration and clear correlation between blood level and clinical response lead us to choose lithium first, everything else being equal. If mixed hypomanic symptoms such as racing thoughts and insomnia improve but do not remit completely, we consider combinations of mood stabilizers such as lithium and carbamazepine, which has been found to have acute antidepressant properties in some cases of bipolar depression [134]. We add an atypical antipsychotic drug if symptoms do not remit with one or a combination of mood stabilizers or if mood improves but psychosis persists. We generally avoid antidepressants unless patients cycle into depression in the absence of any mixed dysphoric hypomanic symptoms such as anxiety, insomnia, irritability, or racing thoughts. We gradually withdraw the antidepressant once depression remits and continue the mood-stabilizing regimen.

In the presence of pervasive or severe psychotic symptoms in unipolar depression, the likelihood of response to an antidepressant alone is low enough for initial treatment with the combination of an antidepressant and an antipsychotic drug to be warranted. The most frequently studied newer antidepressants have been sertraline, fluoxetine, and venlafaxine, while older studies included amitriptyline and nortriptyline. While there is no reason to suppose that any of these antidepressants, or any other antidepressant, is superior to any other, early experience suggests that if an SSRI was not effective, a TCA might be considered [77]. There is also no reason why one antipsychotic drug would be more effective than another, although most published trials have studied olanzapine or perphenazine. We begin with low doses of the antipsychotic drug, but bearing in mind studies suggesting the need for a high antipsychotic dose in some cases, we continue to increase the dose as tolerated in the event of an incomplete response. In the absence of clinical trials in unipolar depression with mild or intermittent psychotic features, our practice has been to initiate treatment with an antidepressant. If this does not produce a robust response, an antipsychotic drug is added. When the response to standard pharmacotherapy is incomplete and ECT is not an immediate option, we augment combination therapy that has been used in other forms of refractory depression such as lithium. As it is not possible to adjust individual doses separately, we avoid fixed antidepressant-antipsychotic combinations such as perphenazine-amitriptyline (Triavil) and olanzapine-fluoxetine (Symbyax).

Despite claims that atypical antipsychotics have antidepressant properties, there is no evidence that monotherapy with an atypical antipsychotic drug is more effective for psychotic unipolar depression than monotherapy with an older antipsychotic. One exception is that the neuroleptic loxapine, which is metabolized to the antidepressant amoxapine, was noted a number of years ago to be almost as effective as combination therapy $[135,136]$. Similarly, amoxapine has sufficient antipsychotic potency to have been used as monotherapy for psychotic unipolar depression $[83,137]$. Both of these medications are used only rarely today, but they are options for patients who do not tolerate or respond to standard combination therapy.

As was noted earlier, limited published long-term studies suggest that antipsychotic drugs should probably be continued for 4-12 months after remission of unipolar psychotic depression. Unless limiting adverse effects emerge, we prefer to continue the antipsychotic for a year after remission of all symptoms. If the patient remains well, we begin to reduce the dose gradually. If either depressive or psychotic symptoms begin to re-emerge, we re-institute the previous dose. Consistent with the treatment of recurrent unipolar nonpsychotic depression or a single severe or dangerous episode, the antidepressant is continued indefinitely.

The substantial morbidity and suicidality associated with psychotic depression leads us to offer ECT as an initial treatment to all patients with psychotic depression as a means of producing a more rapid response with fewer adverse effects. We continue to offer ECT to patients who do not tolerate or respond to combination therapy. Most of the time, we follow a successful course of ECT with maintenance ECT.

Despite the lack of controlled psychotherapy trials in psychotic depression, we consider psychotherapy to be an essential component of any severe mood disorder. Ini- 
tially, we focus on barriers to adherence to medications or consideration of ECT. We find it helpful to involve significant others, both to address their own concerns about treatment and to enlist their help in providing reality testing and encouraging adherence. When patients are less distracted by psychotic experiences, we find it more productive to introduce cognitive techniques, mentalization, and expressive approaches. Following remission, we have found it essential to encourage patient and family to continue follow-up in order to detect and treat early symptoms of relapse.

As with any depressive episode, the goal of treatment of psychotic depression should be complete remission of both depression and psychosis to improve functioning and quality of life and to reduce the risk of major relapse or recurrence. This judgment can be a challenge when patients have been severely ill for some time, since patients and clinicians may be satisfied with a return to functioning or relief of intolerable distress without elimination of all symptoms. Continued adjustment of the regimen requires considerable persistence on the parts of clinicians and patients.

\section{Future Directions}

The acute treatment of definite psychotic unipolar depression seems to be fairly well delineated. However, even after extensive experience over many years, a number of important issues remain to be elucidated. Some patients may require high doses of first-generation antipsychotic medications for a complete response, but it is not known whether the same is true of atypical antipsychotics, which are used more frequently for psychotic depression. It would be desirable to withdraw antipsychotic drugs as soon as possible, or at least within a year, but there are insufficient long-term data to determine whether ongoing antipsychotic treatment at the same or a lower dose is necessary to prevent recurrence, as is the case for antidepressants in nonpsychotic depression. Antipsychotic drugs combined with mood-stabilizing drugs are often integral to the treatment of mania, but it is not yet known whether the combination of an antipsychotic drug and a mood stabilizer is more effective than monotherapy with a mood stabilizer as acute or maintenance treatment of psychotic bipolar depression.

Instrumental therapies such as deep brain stimulation, vagus nerve stimulation, and repetitive transcranial magnetic stimulation have increasingly been studied as interventions for refractory depression, a category that in- cludes a number of patients with psychotic depression. In addition, repetitive transcranial magnetic stimulation may have some applications in the treatment of auditory hallucinations. Controlled studies of these treatments in psychotic depression would certainly be justified, especially for patients with psychotic depression who do not respond to ECT or who cannot tolerate other treatments.

Another source of uncertainty involves the diagnostic and therapeutic significance of mild or transient psychotic symptoms in mood disorders. Do such symptoms, or psychotic symptoms that reflect traumatic experiences such as hearing the voice of an abuse perpetrator or believing that one is under surveillance by a past attacker who has died, qualify as bona fide psychotic symptoms that indicate the need for adjunctive treatment with an antipsychotic drug, or are they in some other category that does not modify treatment of the mood disorder?

One of the most interesting neurobiological uncertainties is the manner in which a liability to psychosis indicated in part by a family history of any psychotic illness interacts with a mood disorder to produce a unique syndrome that is greater than the sum of its parts. Further research that clarifies these issues will undoubtedly lead to more precise treatment of the spectrum of psychotic mood disorders.

\section{Conflict of Interest Statement}

S.L. Dubovsky has received research funding as site principal investigator in multicenter clinical trials from Biogen, Allergan, Intra-Cellular Therapies, Janssen, and Boehringer Ingelheim. B.M. Ghosh has received research funding as site principal investigator in a multicenter study of vagus nerve stimulation from Medtronic. None of the products involved in any of these studies is mentioned in this article, and funding sources played not role in any aspect of preparation of the manuscript. J.C. Serotte and V. Cranwell have no conflicts of interest to declare.

\section{Funding Sources}

The authors have no funding sources to declare.

\section{Author Contributions}

S.L. Dubovsky developed the concept and wrote the first draft. B.M. Ghosh provided additional input and edited the manuscript. J.C. Serotte and V. Cranwell performed research related to the manuscript, reviewed and contributed to editing the manuscript, and provided additional references. 


\section{References}

1 Guze SB, Woodruff RA Jr, Clayton PJ. The significance of psychotic affective disorders. Arch Gen Psychiatry. 1975 Sep;32(9):114750.

2 American Psychiatric Association. Diagnostic and Statistical Manual of Mental Disorders, Second Edition. 2nd ed. Washington, D.C.: American Psychiatric Press, Inc.; 1968.

3 Meyers BS. Psychotic depression. Psychiatr Ann. 2006 Jan;36(1):7-9.

4 Rothschild AJ. Challenges in the treatment of major depressive disorder with psychotic features. Schizophr Bull. 2013 Jul;39(4):787-96.

5 American Psychiatric Association. Diagnostic and Statistical Manual of Mental Disorders, Third Edition. 3 ed. Washington, D.C.: American Psychiatric Press, Inc.; 1980.

6 World Health Organization. International Statistical Classification of Diseases and Related Health Problems. 10th ed. Geneva, Switzerland: World Health Organization; 1994.

7 World Health Organization. International classification of diseases for mortality and morbidity statistics (11th Revision). Geneva, Switzerland: World Health Organization; 2018.

8 Tonna M, De Panfilis C, Provini C, Marchesi C. The effect of severity and personality on the psychotic presentation of major depression. Psychiatry Res. 2011 Nov;190(1):98-102.

9 American Psychiatric Association. Diagnostic and Statistical Manual of Mental Disorders, IV Edition, Text Revised. Washington (D.C.): American Psychiatric Press, Inc.: 2004.

10 American Psychiatric Association. Diagnostic and Statistical Manual of Mental Disorders. 5th ed. Washington (DC): American Psychiatric Press, Inc.; 2013.

11 Park SC, Choi J, Kim JM, Jun TY, Lee MS, $\mathrm{Kim}$ JB, et al. Is the Psychotic Depression Assessment Scale a useful diagnostic tool? The CRESCEND study. J Affect Disord. 2014 Sep 166:79-85.

12 Carlson GA. Affective disorders and psychosis in youth. Child Adolesc Psychiatr Clin N Am. 2013 Oct;22(4):569-80.

13 Østergaard SD, Bille J, Søltoft-Jensen H, Lauge N, Bech P. The validity of the severitypsychosis hypothesis in depression. J Affect Disord. 2012 Sep; 140(1):48-56.

14 Costa FB, Trachtenberg E, Boni A, Primo de Carvalho Alves L, Magalhães PV, Rocha NS. Psychotic depression in hospitalized patients: longitudinal outcomes of psychotic vs. nonpsychotic depression among inpatients. J Psychiatr Res. 2020 Oct;129:73-9.

15 Souery D, Zaninotto L, Calati R, Linotte S, Sentissi O, Amital D, et al. Phenomenology of psychotic mood disorders: lifetime and major depressive episode features. J Affect Disord. 2011 Dec;135(1-3):241-50.

16 Dubovsky SL. Challenges in conceptualizing psychotic mood disorders. Bull Menninger Clin. 1994;58(2):197-214.
17 Owoeye O, Kingston T, Scully PJ, Baldwin P, Browne D, Kinsella A, et al. Epidemiological and clinical characterization following a first psychotic episode in major depressive disorder: comparisons with schizophrenia and bipolar I disorder in the CavanMonaghan First Episode Psychosis Study (CAMFEPS). Schizophr Bull. 2013 Jul;39(4): 756-65.

18 Andreescu C, Mulsant BH, Rothschild AJ, Flint AJ, Meyers BS, Whyte EM. Pharmacotherapy of major depression with psychotic features: what is the evidence? Psychiatr Ann. 2006 Jan;36(1):31-8.

19 DeBattista C, Belanoff J, Glass S, Khan A, Horne RL, Blasey C, et al. Mifepristone versus placebo in the treatment of psychosis in patients with psychotic major depression. Biol Psychiatry. 2006 Dec;60(12):1343-9.

20 Gaudiano BA, Zimmerman M. The relationship between childhood trauma history and the psychotic subtype of major depression. Acta Psychiatr Scand. 2010 Jun;121(6):46270.

21 Wijkstra J, Burger $\mathrm{H}$, van den Broek WW, Birkenhäger TK, Janzing JG, Boks MP, et al. Long-term response to successful acute pharmacological treatment of psychotic depression. J Affect Disord. 2010 Jun;123(1-3):238 42.

22 Flint AJ, Meyers BS, Rothschild AJ, Whyte EM, Mulsant BH, Rudorfer MV, et al.; STOPPD II Study Group. Sustaining remission of psychotic depression: rationale, design and methodology of STOP-PD II. BMC Psychiatry. 2013 Jan;13(1):38.

23 Rothschild AJ, Mulsant BH, Meyers BS, Flint AJ. Challenges in differentiating and diagnosing psychotic depression. Psychiatr Ann. 2006 Jan;36(1):40-6.

24 Buoli M, Caldiroli A, Altamura AC. Psychotic versus non-psychotic major depressive disorder: a comparative naturalistic study. Asian J Psychiatr. 2013 Aug;6(4):333-7.

25 Domschke K. Clinical and molecular genetics of psychotic depression. Schizophr Bull. 2013 Jul;39(4):766-75.

26 Dubovsky SL, Thomas M. Psychotic depression: advances in conceptualization and treatment. Hosp Community Psychiatry. 1992 Dec;43(12):1189-98.

27 David AS, Ajnakina O. Psychosis as a continuous phenotype in the general population: the thin line between normality and pathology. World Psychiatry. 2016 Jun;15(2):129-30.

28 van Os J, Reininghaus U. Psychosis as a transdiagnostic and extended phenotype in the general population. World Psychiatry. 2016 Jun;15(2):118-24.

29 Tamminga CA, Ivleva EI, Keshavan MS, Pearlson GD, Clementz BA, Witte B, et al. Clinical phenotypes of psychosis in the bipolar-schizophrenia network on intermediate phenotypes (B-SNIP). Am J Psychiatry. 2013 Nov;170(11):1263-74.
30 Crow TJ. The continuum of psychosis and its genetic origins. The sixty-fifth Maudsley lecture. Br J Psychiatry. 1990 Jun;156(6):788-97.

31 Pope HG Jr, Lipinski JF Jr. Diagnosis in schizophrenia and manic-depressive illness: a reassessment of the specificity of "schizophrenic" symptoms in the light of current research. Arch Gen Psychiatry. 1978 Jul;35(7): $811-28$

32 van Os J, Linscott RJ, Myin-Germeys I, Delespaul P, Krabbendam L. A systematic review and meta-analysis of the psychosis continuum: evidence for a psychosis proneness-persistence-impairment model of psychotic disorder. Psychol Med. 2009 Feb;39(2):179-95.

33 Crow TJ. Handedness, language lateralisation and anatomical asymmetry: relevance of protocadherin XY to hominid speciation and the aetiology of psychosis. Point of view. Br J Psychiatry. 2002 Oct;181(4):295-7.

34 Crow TJ. How and why genetic linkage has not solved the problem of psychosis: review and hypothesis. Am J Psychiatry. 2007 Jan; 164(1):13-21

35 Tonna M, De Panfilis C, Marchesi C. Moodcongruent and mood-incongruent psychotic symptoms in major depression: the role of severity and personality. J Affect Disord. 2012 Dec;141(2-3):464-8.

36 Goes FS, Zandi PP, Miao K, McMahon FJ, Steele J, Willour VL, et al.; Bipolar Disorder Phenome Group. Mood-incongruent psychotic features in bipolar disorder: familial aggregation and suggestive linkage to $2 \mathrm{p} 11$ q14 and 13q21-33. Am J Psychiatry. 2007 Feb; 164(2):236-47.

37 Harrow M, Grossman LS, Herbener ES, Davies EW. Ten-year outcome: patients with schizoaffective disorders, schizophrenia, affective disorders and mood-incongruent psychotic symptoms. Br J Psychiatry. 2000 Nov; 177(5):421-6.

38 Peralta V, Cuesta MJ. Exploring the borders of the schizoaffective spectrum: a categorical and dimensional approach. J Affect Disord. 2008 May;108(1-2):71-86.

39 Tsuang D, Coryell W. An 8-year follow-up of patients with DSM-III-R psychotic depression, schizoaffective disorder, and schizophrenia. Am J Psychiatry. 1993 Aug;150(8): $1182-8$

40 Gaudiano BA, Uebelacker LA, Miller IW. Course of illness in psychotic mania: is mood incongruence important? J Nerv Ment Dis. 2007 Mar; 195(3):226-32.

41 Østergaard SD, Pedersen CH, Uggerby P, Munk-Jørgensen P, Rothschild AJ, Larsen JI, et al. Clinical and psychometric validation of the psychotic depression assessment scale. J Affect Disord. 2015 Mar; 173:261-8.

42 Goodwin FK, Jamison KR. Manic Depressive Illness. New York: Oxford University Press; 1991. 
43 Strober M, Carlson G. Bipolar illness in adolescents with major depression: clinical, genetic, and psychopharmacologic predictors in a three- to four-year prospective follow-up investigation. Arch Gen Psychiatry. 1982 May;39(5):549-55.

44 Ostergaard SD, Bertelsen A, Nielsen J, Mors O, Petrides G. The association between psychotic mania, psychotic depression and mixed affective episodes among 14,529 patients with bipolar disorder. J Affect Disord. 2013 May; 147(1-3):44-50.

45 Baethge C, Baldessarini RJ, Freudenthal K, Streeruwitz A, Bauer M, Bschor T. Hallucinations in bipolar disorder: characteristics and comparison to unipolar depression and schizophrenia. Bipolar Disord. 2005 Apr; 7(2):136-45.

46 Contreras F, Menchon JM, Urretavizcaya M, Navarro MA, Vallejo J, Parker G. Hormonal differences between psychotic and non-psychotic melancholic depression. J Affect Disord. 2007 Jun; 100(1-3):65-73.

47 Leadholm AK, Rothschild AJ, Nolen WA, Bech P, Munk-Jørgensen P, Ostergaard SD. The treatment of psychotic depression: is there consensus among guidelines and psychiatrists? J Affect Disord. 2013 Feb;145(2): 214-20.

48 Ostergaard SD, Waltoft BL, Mortensen PB, Mors O. Environmental and familial risk factors for psychotic and non-psychotic severe depression. J Affect Disord. 2013 May;147(13):232-40.

49 Ulloa RE, Birmaher B, Axelson D, Williamson DE, Brent DA, Ryan ND, et al. Psychosis in a pediatric mood and anxiety disorders clinic: phenomenology and correlates. J Am Acad Child Adolesc Psychiatry. 2000 Mar; 39(3):337-45

50 Sikich L. Diagnosis and evaluation of hallucinations and other psychotic symptoms in children and adolescents. Child Adolesc Psychiatr Clin N Am. 2013 Oct;22(4):655-73.

51 Davies J, Sullivan S, Zammit S. Adverse life outcomes associated with adolescent psychotic experiences and depressive symptoms. Soc Psychiatry Psychiatr Epidemiol. 2018 May;53(5):497-507.

52 Calkins ME, Moore TM, Satterthwaite TD, Wolf DH, Turetsky BI, Roalf DR, et al. Persistence of psychosis spectrum symptoms in the Philadelphia Neurodevelopmental Cohort: a prospective two-year follow-up. World Psychiatry. $2017 \mathrm{Feb} ; 16(1): 62-76$.

53 Tandon R. Conceptualizing psychotic disorders: don't throw the baby out with the bathwater. World Psychiatry. 2016 Jun;15(2):1334.

54 Parnas J, Henriksen MG. Epistemological error and the illusion of phenomenological continuity. World Psychiatry. 2016 Jun;15(2): 126-7.

55 Yung AR, Lin A. Psychotic experiences and their significance. World Psychiatry. 2016 Jun;15(2):130-1.
56 Bebbington P. Causal narratives and psychotic phenomena. World Psychiatry. 2016 Jun; 15(2):127-8.

57 Meyers BS, English J, Gabriele M, PeasleyMiklus C, Heo M, Flint AJ, et al.; STOP-PD Study Group. A delusion assessment scale for psychotic major depression: Reliability, validity, and utility. Biol Psychiatry. 2006 Dec; 60(12):1336-42.

58 Zimmerman M, Mattia JI. Psychotic subtyping of major depressive disorder and posttraumatic stress disorder. J Clin Psychiatry. 1999 May;60(5):311-4.

59 Hamner MB, Frueh BC, Ulmer HG, Arana GW. Psychotic features and illness severity in combat veterans with chronic posttraumatic stress disorder. Biol Psychiatry. 1999 Apr; 45(7):846-52.

60 Compean E, Hamner M. Posttraumatic stress disorder with secondary psychotic features (PTSD-SP): diagnostic and treatment challenges. Prog Neuropsychopharmacol Biol Psychiatry. 2019 Jan;88:265-75.

61 Clifford G, Dalgleish T, Hitchcock C. Prevalence of auditory pseudohallucinations in adult survivors of physical and sexual trauma with chronic post-traumatic stress disorder (PTSD). Behav Res Ther. 2018 Dec;111:113-

62 Shinn AK, Wolff JD, Hwang M, Lebois LA, Robinson MA, Winternitz SR, et al. Assessing voice hearing in trauma spectrum disorders: a comparison of two measures and a review of the literature. Front Psychiatry. 2020 Feb;10: 1011.

63 Cheng L, Zhu J, Ji F, Lin X, Zheng L, Chen C, et al. Add-on atypical anti-psychotic treatment alleviates auditory verbal hallucinations in patients with chronic post-traumatic stress disorder. Neurosci Lett. 2019 May;701:202-7.

64 Buck B, Norr A, Katz A, Gahm GA, Reger GM. Reductions in reported persecutory ideation and psychotic-like experiences during exposure therapy for posttraumatic stress disorder. Psychiatry Res. 2019 Feb;272:190-5.

65 Serretti A, Mandelli L, Lattuada E, Smeraldi E. Depressive syndrome in major psychoses: a study on 1351 subjects. Psychiatry Res. 2004 Jun;127(1-2):85-99.

66 Fond G, Boyer L, Berna F, Godin O, Bulzacka E, Andrianarisoa M, et al.; FACE-SZ (FondaMental Academic Centers of Expertise for Schizophrenia) group. Remission of depression in patients with schizophrenia and comorbid major depressive disorder: results from the FACE-SZ cohort. Br J Psychiatry. 2018 Aug;213(2):464-70.

67 Hoertel N, Jaffré C, Pascal de Raykeer R, McMahon K, Barrière S, Blumenstock Y, et al.; CSA Study group. Subsyndromal and syndromal depressive symptoms among older adults with schizophrenia spectrum disorder: prevalence and associated factors in a multicenter study. J Affect Disord. 2019 May;251: 60-70.
68 Bornheimer LA. Suicidal ideation in first-episode psychosis (FEP): examination of symptoms of depression and psychosis among individuals in an early phase of treatment. Suicide Life Threat Behav. 2019 Apr;49(2): 423-31.

69 Krynicki CR, Upthegrove R, Deakin JF, Barnes TR. The relationship between negative symptoms and depression in schizophrenia: a systematic review. Acta Psychiatr Scand. 2018 May;137(5):380-90.

70 Palomba A, Lodovighi MA, Belzeaux R, Adida M, Azorin JM. Use of antidepressants in the treatment of negative symptoms of schizophrenia. Encephale. 2015 Dec;41(6 Suppl 1): 6S36-40. French.

71 Helfer B, Samara MT, Huhn M, Klupp E, Leucht C, Zhu Y, et al. Efficacy and safety of antidepressants added to antipsychotics for schizophrenia: A systematic review and metaanalysis. Am J Psychiatry. 2016 Sep;173(9): 876-86.

72 Moazen-Zadeh E, Bayanati S, Ziafat K, Rezaei F, Mesgarpour B, Akhondzadeh S. Vortioxetine as adjunctive therapy to risperidone for treatment of patients with chronic schizophrenia: A randomised, double-blind, placebo-controlled clinical trial. J Psychopharmacol. 2020 May;34(5):506-13.

73 Barnes TR, Leeson VC, Paton C, Costelloe C, Simon J, Kiss N, et al. Antidepressant Controlled Trial For Negative Symptoms In Schizophrenia (ACTIONS): a double-blind, placebo-controlled, randomised clinical trial. Health Technol Assess. 2016 Apr;20(29):146.

74 van Rooijen G, Vermeulen JM, Ruhé HG, de Haan L. Treating depressive episodes or symptoms in patients with schizophrenia. CNS Spectr. 2019 Apr;24(2):239-48.

75 Vanelle JM, Douki S. A double-blind randomised comparative trial of amisulpride versus olanzapine for 2 months in the treatment of subjects with schizophrenia and comorbid depression. Eur Psychiatry. 2006 Dec;21(8): 523-30.

76 Englisch S, Jung HS, Lewien A, Becker A, Nowak U, Braun $\mathrm{H}$, et al. Agomelatine for the treatment of major depressive episodes in schizophrenia-spectrum disorders: an openprospective proof-of-concept study. J Clin Psychopharmacol. 2016 Dec;36(6):597-607.

77 Glassman AH, Roose SP. Delusional depression. A distinct clinical entity? Arch Gen Psychiatry. 1981 Apr;38(4):424-7.

78 Frances A, Brown RP, Kocsis JH, Mann JJ. Psychotic depression: a separate entity? Am J Psychiatry. 1981 Jun;138(6):831-3.

79 Meyers BS, Peasley-Miklus C, Flint AJ, Mulsant $\mathrm{BH}$, Rothschild AJ. Methodological issues in designing a randomized controlled trial for psychotic depression: the STOP-PD Study. Psychiatr Ann. 2006 Jan;36(1):57-64.

80 Mapother E. Discussion on manic-depressive psychosis. BMJ. 1926 Nov;2:872-9. 
81 Rückl S, Gentner NC, Büche L, Backenstrass $\mathrm{M}$, Barthel A, Vedder H, et al. Coping with delusions in schizophrenia and affective disorder with psychotic symptoms: the relationship between coping strategies and dimensions of delusion. Psychopathology. 2015; 48(1):11-7.

82 Wijkstra J, Lijmer J, Burger H, Cipriani A, Geddes J, Nolen WA. Pharmacological treatment for psychotic depression. Cochrane $\mathrm{Da}-$ tabase Syst Rev. 2015 Jul;7(7):CD004044.

83 Anton RF Jr, Burch EA Jr. Amoxapine versus amitriptyline combined with perphenazine in the treatment of psychotic depression. Am J Psychiatry. 1990 Sep;147(9):1203-8.

84 Farahani A, Correll CU. Are antipsychotics or antidepressants needed for psychotic depression? A systematic review and meta-analysis of trials comparing antidepressant or antipsychotic monotherapy with combination treatment. J Clin Psychiatry. 2012 Apr;73(4):48696.

85 Meyers BS, Klimstra SA, Gabriele M, Hamilton M, Kakuma T, Tirumalasetti F, et al. Continuation treatment of delusional depression in older adults. Am J Geriatr Psychiatry. 2001; 9(4):415-22.

86 Janicak PG, Pandey GN, Davis JM, Boshes R, Bresnahan D, Sharma R. Response of psychotic and nonpsychotic depression to phenelzine. Am J Psychiatry. 1988 Jan;145(1):935.

87 Rothschild AJ, Williamson DJ, Tohen MF, Schatzberg A, Andersen SW, Van Campen LE, et al. A double-blind, randomized study of olanzapine and olanzapine/fluoxetine combination for major depression with psychotic features. J Clin Psychopharmacol. 2004 Aug;24(4):365-73.

88 Meyers BS, Flint AJ, Rothschild AJ, Mulsant $\mathrm{BH}$, Whyte EM, Peasley-Miklus $\mathrm{C}$, et al.; STOP-PD Group. A double-blind randomized controlled trial of olanzapine plus sertraline vs olanzapine plus placebo for psychotic depression: the study of pharmacotherapy of psychotic depression (STOP-PD). Arch Gen Psychiatry. 2009 Aug;66(8):838-47.

89 Østergaard SD, Meyers BS, Flint AJ, Mulsant $\mathrm{BH}$, Whyte EM, Ulbricht CM, et al.; STOPPD Study Group. Measuring treatment response in psychotic depression: the Psychotic Depression Assessment Scale (PDAS) takes both depressive and psychotic symptoms into account. J Affect Disord. 2014 May;160:6873.

90 Østergaard SD, Meyers BS, Flint AJ, Mulsant $\mathrm{BH}$, Whyte EM, Ulbricht CM, et al.; STOPPD Study Group. Measuring psychotic depression. Acta Psychiatr Scand. 2014 Mar; 129(3):211-20

91 Østergaard SD, Rothschild AJ, Flint AJ, Mulsant $\mathrm{BH}$, Whyte EM, Vermeulen T, et al. Establishing the cut-off score for remission and severity-ranges on the Psychotic Depression Assessment Scale (PDAS). J Affect Disord. 2016 Jan;190:111-4.
92 Wijkstra J, Burger H, van den Broek WW, Birkenhäger TK, Janzing JG, Boks MP, et al. Treatment of unipolar psychotic depression: a randomized, double-blind study comparing imipramine, venlafaxine, and venlafaxine plus quetiapine. Acta Psychiatr Scand. 2010 Mar;121(3):190-200.

93 Nelson JC, Price LH, Jatlow PI. Neuroleptic dose and desipramine concentrations during combined treatment of unipolar delusional depression. Am J Psychiatry. 1986 Sep;143(9):1151-4.

94 Blumberger DM, Mulsant BH, Kanellopoulos D, Whyte EM, Rothschild AJ, Flint AJ, et al. The incidence of tardive dyskinesia in the study of pharmacotherapy for psychotic depression. J Clin Psychopharmacol. 2013 Jun;33(3):391-7.

95 Parker G, Roy K, Hadzi-Pavlovic D, Pedic F. Psychotic (delusional) depression: a metaanalysis of physical treatments. J Affect Disord. 1992 Jan;24(1):17-24.

96 Wijkstra J, Lijmer J, Balk FJ, Geddes JR, Nolen WA. Pharmacological treatment for unipolar psychotic depression: systematic review and meta-analysis. Br J Psychiatry. 2006 May; 188(5):410-5.

97 Wigman JT, van Os J, Abidi L, Huibers MJ, Roelofs J, Arntz A, et al. Subclinical psychotic experiences and bipolar spectrum features in depression: association with outcome of psychotherapy. Psychol Med. 2014 Jan;44(2):325-36

98 Schrank B, Brownell T, Jakaite Z, Larkin C, Pesola F, Riches S, et al. Evaluation of a positive psychotherapy group intervention for people with psychosis: pilot randomised controlled trial. Epidemiol Psychiatr Sci. 2016 Jun;25(3):235-46

99 Klingberg S, Hesse K. Differential indication for psychotherapy in psychosis: are there evidence-based criteria? Nervenarzt. 2018 Mar;89(3):276-82. German.

100 de Jong S, van Donkersgoed RJ, Timmerman ME, Aan Het Rot M, Wunderink L, Arends J, et al. Metacognitive reflection and insight therapy (MERIT) for patients with schizophrenia. Psychol Med. 2019 Jan; 49(2):303-13.

101 Shader RI. Psychosis and Psychotherapy. J Clin Psychopharmacol. 2019 Nov/Dec; 39(6):541-2.

102 Zhou X, Teng T, Zhang Y, Del Giovane C, Furukawa TA, Weisz JR, et al. Comparative efficacy and acceptability of antidepressants, psychotherapies, and their combination for acute treatment of children and adolescents with depressive disorder: a systematic review and network meta-analysis. Lancet Psychiatry. 2020 Jul;7(7):581-601.

103 Cox GR, Callahan P, Churchill R, Hunot V, Merry SN, Parker AG, et al. Psychological therapies versus antidepressant medication, alone and in combination for depression in children and adolescents. Cochrane Database Syst Rev. 2012 Nov;11:CD008324.
104 Anagnostopoulou N, Kyriakopoulos M, Alba A. Psychological interventions in psychosis in children and adolescents: a systematic review. Eur Child Adolesc Psychiatry. 2019 Jun;28(6):735-46.

105 Kessler AJ, Barklage NE, Jefferson JW. Mood disorders in the psychoneurologic borderland: three cases of responsiveness to carbamazepine. Am J Psychiatry. 1989 Jan; 146(1):81-3

106 Simpson GM, El Sheshai A, Loza N, Kingsbury SJ, Fayek M, Rady A, et al. An 8-week open-label trial of a 6-day course of mifepristone for the treatment of psychotic depression. J Clin Psychiatry. 2005 May;66(5): 598-602.

107 Blasey CM, Debattista C, Roe R, Block T, Belanoff JK. A multisite trial of mifepristone for the treatment of psychotic depression: a site-by-treatment interaction. Contemp Clin Trials. 2009 Jul;30(4):284-8.

108 Tohen M, Khalsa HK, Salvatore P, Vieta E, Ravichandran C, Baldessarini RJ. Two-year outcomes in first-episode psychotic depression the McLean-Harvard First-Episode Project. J Affect Disord. 2012 Jan;136(1-2): $1-8$

109 Coryell W, Leon A, Winokur G, Endicott J, Keller M, Akiskal H, et al. Importance of psychotic features to long-term course in major depressive disorder. Am J Psychiatry. 1996 Apr;153(4):483-9.

110 Winokur G. Psychosis in bipolar and unipolar affective illness with special reference to schizo-affective disorder. Br J Psychiatry. 1984 Sep;145(3):236-42.

111 Coryell W, Zimmerman M, Pfohl B. Outcome at discharge and six months in major depression. The significance of psychotic features. J Nerv Ment Dis. 1986 Feb;174(2): 92-6.

112 Clower CG. Recurrent psychotic unipolar depression. J Clin Psychiatry. 1983 Jun; 44(6):216-8

113 Kettering RL, Harrow M, Grossman L, Meltzer HY. The prognostic relevance of delusions in depression: a follow-up study. Am J Psychiatry. 1987 Sep;144(9):1154-60.

114 Aronson TA, Shukla S, Gujavarty K, Hoff A, DiBuono M, Khan E. Relapse in delusional depression: a retrospective study of the course of treatment. Compr Psychiatry. 1988 Jan-Feb;29(1):12-21.

115 Flint AJ, Meyers BS, Rothschild AJ, Whyte EM, Alexopoulos GS, Rudorfer MV, et al.; STOP-PD II Study Group. Effect of Continuing Olanzapine vs Placebo on Relapse Among Patients With Psychotic Depression in Remission: The STOP-PD II Randomized Clinical Trial. JAMA. 2019 Aug;322(7): $622-31$. 
116 Voineskos AN, Mulsant BH, Dickie EW, Neufeld NH, Rothschild AJ, Whyte EM, et al. Effects of antipsychotic medication on brain structure in patients with major depressive disorder and psychotic features: neuroimaging findings in the context of a randomized placebo-controlled clinical trial. JAMA Psychiatry. 2020 Jul;77(7):674-83.

117 Coryell WH. Maintenance treatment for psychotic depressive disorders: progress and remaining challenges. JAMA. 2019 Aug;322(7):615-7.

118 Coryell W. Psychotic depression. J Clin Psychiatry. 1996;57(Suppl 3):27-31.

119 Strober M, Lampert C, Schmidt S, Morrell $\mathrm{W}$. The course of major depressive disorder in adolescents: I. Recovery and risk of manic switching in a follow-up of psychotic and nonpsychotic subtypes. J Am Acad Child Adolesc Psychiatry. 1993 Jan;32(1):34-42.

120 Ghaemi SN, Boiman EE, Goodwin FK. Diagnosing bipolar disorder and the effect of antidepressants: a naturalistic study. J Clin Psychiatry. 2000 Oct;61(10):804-8.

121 Das AK, Olfson M, Gameroff MJ, Pilowsky DJ, Blanco C, Feder A, et al. Screening for bipolar disorder in a primary care practice. JAMA. 2005 Feb;293(8):956-63.

122 Angst J, Cui L, Swendsen J, Rothen S, Cravchik A, Kessler RC, et al. Major depressive disorder with subthreshold bipolarity in the National Comorbidity Survey Replication. Am J Psychiatry. 2010 Oct;167(10):1194201.

123 Cheniaux E, Silva RA, Santana CM, Nardi $\mathrm{AE}$, Filgueiras A. Mood versus energy/activity symptoms in bipolar disorder: which cluster of Hamilton Depression Rating Scale better distinguishes between mania, depression, and euthymia? Trends Psychiatry Psychother. 2019 Oct-Dec;41(4):401-8.
124 Ghaemi SN, Rosenquist KJ, Ko JY, Baldassano CF, Kontos NJ, Baldessarini RJ. Antidepressant treatment in bipolar versus unipolar depression. Am J Psychiatry. 2004 Jan; 161(1):163-5.

125 Leverich GS, Altshuler LL, Frye MA, Suppes T, McElroy SL, Keck PE Jr, et al. Risk of switch in mood polarity to hypomania or mania in patients with bipolar depression during acute and continuation trials of venlafaxine, sertraline, and bupropion as adjuncts to mood stabilizers. Am J Psychiatry. 2006 Feb;163(2):232-9.

126 Strejilevich SA, Martino DJ, Marengo E, Igoa A, Fassi G, Whitham EA, et al. Longterm worsening of bipolar disorder related with frequency of antidepressant exposure. Ann Clin Psychiatry. 2011 Aug;23(3):18692.

127 Thase ME, Macfadden W, Weisler RH, Chang W, Paulsson B, Khan A, et al.; BOLDER II Study Group. Efficacy of quetiapine monotherapy in bipolar I and II depression: a double-blind, placebo-controlled study (the BOLDER II study). J Clin Psychopharmacol. 2006 Dec;26(6):600-9.

128 Loebel A, Cucchiaro J, Silva R, Kroger H, Hsu J, Sarma K, et al. Lurasidone monotherapy in the treatment of bipolar I depression: a randomized, double-blind, placebo-controlled study. Am J Psychiatry. 2014 Feb; 171(2):160-8

129 Brown ES, Khaleghi N, Van Enkevort E, Ivleva E, Nakamura A, Holmes T, et al. A pilot study of brexpiprazole for bipolar depression. J Affect Disord. 2019 Apr;249:315-8.
130 Earley W, Burgess MV, Rekeda L, Dickinson R, Szatmári B, Németh G, et al. Cariprazine treatment of bipolar depression: a randomized double-blind placebo-controlled phase 3 study. Am J Psychiatry. 2019 Jun; 176(6):439-48.

131 Goodwin FK, Whitham EA, Ghaemi SN Maintenance treatment study designs in bipolar disorder: do they demonstrate that atypical neuroleptics (antipsychotics) are mood stabilizers? CNS Drugs. 2011 Oct; 25(10):819-27.

132 de Sousa RT, Busnello JV, Forlenza OV, Zanetti MV, Soeiro-de-Souza MG, van de Bilt MT, et al. Early improvement of psychotic symptoms with lithium monotherapy as a predictor of later response in mania. J Psychiatr Res. 2012 Dec;46(12):1564-8.

133 Dubovsky SL. Treatment of bipolar depression. Psychiatr Clin North Am. 2005 Jun; 28(2):349-70.

134 Post RM, Uhde TW, Roy-Byrne PP, Joffe RT. Antidepressant effects of carbamazepine. Am J Psychiatry. 1986 Jan;143(1):2934.

135 Goldschmidt TJ, Burch EA Jr. Use of loxapine to treat a patient with psychotic depression. Am J Psychiatry. 1982 Jul;139(7):9467.

136 Burch EA Jr, Goldschmidt TJ. Loxapine in the treatment of psychotic-depressive disorders: measurement of antidepressant metabolites. South Med J. 1983 Aug;76(8):9915.

137 Kapur S, Cho R, Jones C, McKay G, Zipursky RB. Is amoxapine an atypical antipsychotic? Positron-emission tomography investigation of its dopamine 2 and serotonin2 occupancy. Biol Psychiatry. 1999 May; 45(9):1217-20. 